\title{
MOVIMENTOS ÉTNICOS BOLIVIANOS E SUA LUTA PELO RECONHECIMENTO DE PRINCÍPIOS INDÍGENAS NO DIREITO ESTATAL
}

\author{
Aline de Souza Vasconcellos do Valle*
}

\section{Resumo}

A história dos povos indígenas bolivianos foi marcada pela luta diante da força do colonizador, continuando após a independência diante da perpetuação da colonialidade do poder. Durante o século XX, diferentes programas estatais tentaram resolver o "problema índio" seja pela tentativa de aniquilação desses povos, seja pela integração à cultura branca. Contudo, a força dos programas estatais não foi suficiente para bloquear o ressurgimento do movimento étnicos a partir de 1970 e sua luta por direitos. Diante deste contexto, o artigo analisa a formação dos movimentos étnicos bolivianos e sua relação com o Direito como ferramenta de emancipação.

Palavras-chave: Movimentos indígenas; Direito indígena; conflitos étnicos; História da América latina; Direitos Humanos.

\section{BOLIVIAN ETHNIC MOVEMENTS AND THEIR STRUGGLE FOR THE RECOGNITION OF INDIGENOUS PRINCIPLES IN STATE LAW}

\begin{abstract}
The history of the Bolivian indigenous peoples was marked by the struggle in the face of the strength of the colonizer, continuing after independence in the face of the perpetuation of the coloniality of power. During the 20th century, different state programs attempted to solve the "Indian problem". However, the strength of state programs was not sufficient to block the resurgence of the ethnic movement from 1970 onwards and its struggle for rights. In this context, the article analyzes the formation of Bolivian ethnic movements and their relationship with law as a tool for emancipation.
\end{abstract}

Keywords: Indigenous movements; Indigenous law; ethnic conflicts; Latin American history; Human rights.

\section{TRÊS SÉCULOS DE LUTA POR DIREITOS INDÍGENAS}

$\mathrm{Na}$ Bolívia, os levantamentos indígenas se fizeram comuns desde o fim do século XVIII, mas com o início da república em 1825, a exclusão e a marginalização de grupos indígenas pelas elites foram intensificadas. Em 1874 foi posta em marcha a Lei de exvinculacíón, com o objetivo de ampliar o sistema de haciendas. Diferente do período colonial,

\footnotetext{
* Graduada em Direito (FDV) e História (UFES). Mestre em História pela UFES. Doutoranda em História pelo Programa de Pós-Graduação em História Social das Relações Políticas da Universidade Federal do Espírito Santo. Bolsista do Programa Pesquisa Produtividade da FESVV - Faculdade Estácio de Vila Velha.. E-mail: alinevdovalle@gmail.com.br.
} 
quando a comunidade se mantinha em troca do pagamento do tributo e do trabalho forçado (mita), com a Lei de ex-vinculacíón as comunidades indígenas desapareceriam nas mãos de compradores de terra que as converteriam em haciendas. No caso do altiplano, os indígenas das terras comunais foram submetidos à força ao sistema de colonato e ao regime de servidão (pongueaje) nas haciendas, com a acentuação da discriminação. Já nesta época, o projeto de difusão da língua espanhola e da escrita gerou o movimento de indígenas conhecidos como "caciques apoderados", que exigiram a manutenção das terras comunais herdadas por títulos coloniais (URIOSTE, 2007, XLVII).

Contudo, o século XX pode ser apontado como ápice das movimentações sociais e das diferentes políticas públicas quanto ao indígena no país, passando desde a identificação do indígena enquanto camponês, forma encontrada para incorporá-lo ao conceito de classe e ensejar a sua sindicalização, até a formação de organizações e movimentos indígenas que se colocaram para além da política estatal ou movimentos que através de alianças formaram partidos étnicos que passaram a atuar por meio da política eleitoral estatal (BELLO, 2004, p. 95).

Bello (2004, p. 95) destaca o papel da Guerra do Chaco $(1932-1935)^{\dagger}$ como fato histórico que levou a um giro para a Bolívia atual e para a redefinição da política em relação ao indígena pois, para este autor, quando a Bolívia foi derrotada pelo Paraguai, ficaram expostas a corrupção e a incapacidade da elite governante que levou o conflito adiante, o que somado à falta de adesão dos grupos étnicos ao conflito, ocasionou uma reação de amplos setores da sociedade e fez surgir uma das primeiras correntes indigenistas e os primeiros partidos de esquerda. Logo chegaram ao poder governos militares (1936 - 1946) que iniciaram políticas para atrair e incorporar as populações quéchua e aimará, com congressos indígenas que foram apoiados por sindicatos e universitários. Porém, em 1952 aconteceu um levantamento sem precedentes, encabeçado pelo Movimento Nacionalista Revolucionário (MNR) e juntamente com a Central Obreira Boliviana (COB) formaram uma aliança para derrubar o regime que havia se instalado.

\footnotetext{
† A derrota na Guerra do Chaco (1932-1935), com a consequente humilhação, perda de territórios e agudização da crise econômica, provocou o desprestígio do Exército, responsabilizado, junto com a "rosca"- nome dado à elite mineradora, por se considerar que girava em torno dos próprios interesses - pelo fracasso (AYERBE, 2011, p. 182).
} 
O MNR estabeleceu um processo de rompimento com a política de exclusão do indígena mantida por governos anteriores, além de fortalecer os sindicatos, nacionalizar as mineradoras e iniciar uma política de reforma agrária (1953) que teve como base a sindicalização do indígena, o voto, além de estabelecer a obrigatoriedade da educação universal e gratuita, com forte impacto na formação de lideranças intelectuais indígenas futuras. O direito ao voto indígena e camponês fez quintuplicar o eleitorado e, a partir de 1952, os indígenas passaram a ser identificados pelo Estado como classe camponesa, devido à influência da COB (BELLO, 2004, p. 95).

A política de assimilação do indígena iniciada pelo MNR estabeleceu como objetivo central para resolver o "problema índio" o oferecimento da educação formal, esperança de que o indígena deixasse suas "superstições" e crenças consideradas irracionais. Paradoxalmente a política quanto ao indígena iniciada em 1952 propiciou o crescimento do número de indígenas educados em instituições superiores e universidades, que passaram a atuar politicamente e a questionar a escrita da história boliviana, formando centros culturais e políticos que buscavam a construção da história dos povos indígenas bolivianos por meio da história oral, num processo de fortalecimento das identidades e tomada de consciência da necessidade de autonomia (CHOQUE; MAMANI, 2003, p. 205). Não obstante a política educacional promovida pelo MNR, suas medidas não foram suficientes para estabilizar a economia do país e diante do aumento da inflação, manifestações sociais estouravam nos setores médios urbanos e operário, levando o país a um golpe militar em 1964, dando início a uma série de governos que levaram o país a mais instabilidade política e econômica (AYERBE, 2011, p. 184).

Nos primeiros anos da ditadura militar boliviana (1964-1982), especialmente durante o governo de Barrientos (1964-1969) se estabeleceu o "Pacto Militar-Camponês" promovendo o monopólio das Forças Armadas sobre os sindicatos, realizando o controle preventivo de manifestações contrárias ao governo, além de utilizar a entrega de títulos de terra às comunidades rurais como moeda de troca para conseguir a adesão das lideranças sindicais indígenas e apoios políticos (URIOSTE, 2007, L).

Porém, durante o governo de Hugo Banzer (1971-1978) o discurso de conciliação entre camponeses e governo se desfaz, pois, diferente dos primeiros anos do Pacto, a ditadura 
de Banzer estabeleceu um discurso modernizante que privilegiava a agroindústria capitalista em detrimento do cultivo tradicional (RIVERA CUSICANQUI, 2010, p. 46).

Este desencontro entre os interesses camponeses/indígenas e do governo eclodiu nos bloqueios de Tolala, Melga e Epizana, na região dos vales de Cochabamba, em janeiro de 1974. O aparato sindical da região dos vales, onde aconteceram os bloqueios, estava abalado por lutas de facções entre esquerdistas (contrários ao governo de Banzer) e nacionalistas (defensores da continuidade do Pacto Militar-Camponês). Este cenário de lutas se intensificou com a publicação do decreto de 20 de janeiro de 1974 que determinava uma alta de mais de $100 \%$ em vários produtos alimentícios básicos, detonando uma série de mobilizações na região dos vales (RIVERA CUSICANQUI, 2010, p. 27).

O movimento teve início em 21 de janeiro, com a concentração de trabalhadores numa rodovia de "Quillacoll" e se encerrou oito dias depois com uma multidão metralhada pelas forças militares do governo. As dissidências dentro dos sindicatos se acirravam devido a uma nova geração, que chegava a alguns postos de liderança dos sindicatos, e que começava a contestar a política clientelista e paternalista estabelecida dentro do Pacto, além de retomar uma leitura étnica da realidade, pensando a rearticulação entre os conceitos de classe e etnia (DO ALTO, 2007, p. 31).

Os acontecimentos em Tolata e o enfraquecimento do Pacto Militar-Camponês juntamente com o aprofundamento da crise econômica durante o governo Banzer, atuaram como incentivo para a retomada da luta étnica, desarticulando os últimos níveis de efetividade do discurso da Revolução de 1952, que se estruturava na primazia do Estado como agente econômico e no camponês como base de manutenção desta política (PANNAIN, 2014, p. 72).

É possível perceber que tanto nos primeiros anos do pós-independência, em que predominou o alijamento do indígena em relação à política nacional, quanto no Pacto MilitarCamponês, quando o trabalho de incorporação do indígena levou às tentativas de identificação dos grupos étnicos como classe camponesa, o referencial presente em relação à "questão indígena" esteve fundamentado numa percepção eurocêntrica da política e da formação e desenvolvimento de um Estado Nacional homogêneo, capitaneado pelos ideais europeus de soberania, população e território (PANNAIN, 2014, p. 72). 
De acordo com Albó (2002, p. 32), desde o avanço do processo de reforma agrária iniciado pelo MNR, houve um esforço por esquecer a questão étnica e substituir a palavra "índio" pela palavra "camponês", associando-se o nome "indígena" aos habitantes da selva, mas mesmo em relação a estes últimos, a palavra "comunidade" foi esquecida, falando-se em sindicatos, cooperativas ou produtores agrários, com governos que apostavam na mestiçagem. Segundo o mesmo autor, a política de mestiçagem foi compartilhada pela direita e pela esquerda, com o objetivo de suprimir a identidade étnica frente à identidade nacional, homogênea. Contudo, na década de 1970 começou o que Albó denomina um "despertar étnico".

Como mencionado acima, o governo de Hugo Banzer pode ser apontado como um período importante para a análise da retomada do discurso étnico, quando o endurecimento da repressão contra camponeses, mineradores e contra a própria COB (Central Obrera Boliviana) levou a uma renovação dos postos de liderança dentro dos sindicatos camponeses, em detrimento de caciques e líderes locais alinhados ao Pacto. O VI Congresso da CNTCB (Confederación Nacional de los Trabajadores Campesinos de Bolivia) em 1971 marcou o momento de uma mudança estrutural dentro desta organização camponesa/indígena criada pelo MNR em 1954, com a eleição de uma geração de líderes sindicais que se identificavam como indígenas e Kataristas. Jenaro Flores (aimará proveniente de La Paz), que neste congresso assumiu o cargo de secretário executivo da CNTCB, tornou-se símbolo desta nova geração que negava o Pacto Militar-Camponês com um discurso de revalorização "do índio", trazendo uma leitura étnica da sociedade e uma rearticulação entre classe e etnia (DO ALTO, 2007, p. 28).

Sendo um movimento de inspiração indígena, baseado na luta do líder Tupac Katari, que comandou um levante do povo aimará contra o governo colonial em 1780, o Katarismo ${ }^{\S}$ foi um dos grandes difusores da ideia de identidade étnica e da necessidade de um Estado pluriétnico, com papel fundamental durante a década de 1970, tendo como consequência a

\footnotetext{
${ }^{\ddagger}$ Concomitantemente à Reforma Agrária iniciada em 1953, o MNR criou uma organização sindical "camponesa” de caráter nacional, chamada Confederação Nacional de Trabalhadores Campesinos da Bolívia (CNTCB). GIANOTTEN 2006. p.41.

${ }^{\S}$ As origens do Katarismo remontam ao final da década de 1960, quando grupos de estudantes aimarás em La $\mathrm{Paz}$, vindos das zonas rurais, formaram várias organizações para representar seus interesses e defender-se coletivamente da discriminação que enfrentavam. O Katarismo englobou uma série de movimentos de contestação ao paternalismo estatal e à política da mestiçagem que começou com o Movimento de 1952. ESCARZÁGA 2012, p. 188.
} 
formação de importantes lideranças políticas e intelectuais que auxiliaram no fortalecimento étnico de sindicatos locais criados durante os governos do MNR e participação no surgimento de partidos étnicos nas décadas de 1980 e 1990, expressando diferentes correntes de pensamento. (GARCÍA LINERA, 2009).

Rivera Cusiquanqui também aponta a década de 1970 como período de surgimento de movimentos étnicos que passaram a buscar autonomia em relação à tutela estatal. Para a autora, o momento de retomada de consciência étnica na Bolívia pode ser dividido em duas frentes: entre camponeses, de regiões como Santa Cruz, Alto Beni (La Paz) e Chapare e de jovens que migram para as cidades alcançando educação média e superior, como resultado do movimento de 1952 e de sua política integracionista por meio da educação Os camponeses, em sua maioria indígenas, vão tomando consciência das novas contradições decorrentes da influência do capitalismo no setor agrário, como o crescimento da subordinação da economia familiar à estrutura monopolista do mercado, a formação de uma massa assalariada agrícola que passa a alimentar a produção empresarial da cana-de-açúcar, do algodão, da coca e da soja, juntamente com grupos de mineiros, progressivamente despedidos das minas e reprimidos pelo Estado em suas manifestações, formando organizações com maior autonomia e desvinculadas dos aparatos sindicais oficialistas (RIVERA CUSICANQUI, 2010, p. 176).

Diante desse contexto, na zona rural, o katarismo encontrou espaço fértil entre os jovens que nasceram após o movimento de 1952. Essa juventude, fruto da reforma agrária, da educação rural e da nova economia mercantil, conseguiu perceber e criticar as distorções presentes na estrutura dos sindicatos herdados de 1952, o servilismo e a corrupção dos velhos dirigentes e o desprezo dos criollos pelos valores, formas de comportamento e organização dos povos andinos, ficando mais evidente para estes jovens a realidade de castelhanização, de paternalismo e manipulação que perpassava o manejo oficial quanto ao "problema camponês", denunciando as continuidades oligárquicas e senhoriais, pois eram oficialmente iguais, mas impedidos de exercer suas diferenças (RIVERA CUSICANQUI, 2010, p. 181).

Outro ponto relevante para analisar a retomada do discurso étnico na Bolívia está na existência de uma sobreposição da estrutura sindical camponesa criada com a Revolução de 1952 às estruturas tradicionais de uso da terra e organização das comunidades indígenas. Para Gianotten (2006, p. 41), muito embora as terras comunais também tenham sido identificadas 
como sindicatos e a população indígena dividida pela filiação sindical, passando a ser parte dessa estrutura nacional ligada ao governo, estes "sindicatos" criados artificialmente, não tinham a organização típica e reivindicativa que caracterizavam o movimento obreiro, mantendo o caráter de organização das comunidades e terras comunais existentes antes de sua criação, onde, muitas vezes, coexistiam autoridades tradicionais ao lado das autoridades "sindicais". Assim, juntamente com a estrutura sindical, permaneceu latente a estrutura indígena, comunal, estabelecendo uma ligação entre as demandas governamentais pela integração classista e as demandas decorrentes da identidade étnica.

Desta maneira, ao analisar a história da Bolívia no século XX, nota-se um entrelaçamento entre as estruturas sindicais e os movimentos indígenas, com diferentes graus de efetividade do dirigismo e limitações estabelecidas pelo governo entre as comunidades indígenas. Por outro lado, a experiência adquirida durante os anos de participação como membros, dentro dos sindicatos oficialistas e a convivência com lideranças advindas do movimento de mineiros, foi apropriada pelos grupos étnicos. A partir da década de 1970 e principalmente após o fim da ditadura, essa "experiência sindical" foi utilizada para a configuração de múltiplas associações que embora utilizando-se de denominações que fazem acreditar em formações sindicais e classistas, na verdade fundamentavam-se na negação da estrutura corrompida das antigas instituições apoiadas pelos governos ditatoriais (GIANOTTEN, 2006, p. 41).

Segundo Rivera Cusiquanqui (2010, p. 177), no mesmo período, cidades como La Paz, já estavam tomadas por migrantes aimarás (em 1976, dados do censo dão conta que 48\% dos habitantes de La Paz eram aimarás), formando uma subcultura urbana com traços de cultura originária, contando com múltiplos mecanismos, formais e informais, de difusão cultural, como programas de rádio em aimará, centros culturais que serviam de ponte para a relação dos migrantes com suas regiões de origem. Devido ao tipo de inserção que tiveram no meio urbano, esses indígenas, de maneira geral puderam perceber as permanências da mentalidade colonial e racista que predominava entre os grupos criollos da sociedade, vivendo cotidianamente a discriminação e a exclusão, uma vez que a inserção do indígena na sociedade pós-revolucionária acabou por acentuar a percepção em relação à resistência que encontraram no meio urbano. 
Como consequência da discriminação nas grandes cidades, cresceu o número de jovens indígenas que passaram a rejeitar as propostas de adequação ao ideal de prosperidade por meio do trabalho nas grandes cidades, surgindo intelectuais que buscaram expressar as frustrações da experiência urbana, formando vários grupos de estudo e associações estudantis que reivindicavam as lutas anticoloniais, buscando o vínculo entre todos os indígenas bolivianos. Estes movimentos culturais e políticos de setores urbanos fizeram parte da base do movimento katarista. Um dos aspectos fundamentais para o crescimento katarista foi a interação entre os participantes dos movimentos indígenas urbanos e o "sindicalismo" de base do altiplano, levando também à derrota de grupos que apoiavam o governo nas principais votações para representação de organismos camponeses e mineiros do país (GIANOTTEN, 2006, p. 45).

Além do rompimento do Pacto Militar-Camponês e do Katarismo, segundo Albó (2002, p. 32), é preciso destacar o papel de setores que denominou "inovadores", "menos proselitistas" e "mais comprometidos" dentro da Igreja Católica, e sua contribuição para a retomada étnica, tendo como forte incentivo as consequências do Concílio Vaticano II (1961) e da Conferência de Medellín (1968), documentos que expressaram a necessidade de atuação da Igreja Católica junto às populações pobres, além de trazer princípios como a dignidade humana. Para Albó (2002, p. 32), a Igreja e a Teologia da Libertação foram muito importantes no processo de fortalecimento dos movimentos étnicos foi atuante em países como Peru, Equador e Bolívia. Também afirma que com os anos, determinados setores de outras igrejas cristãs históricas, como os metodistas, luteranos e outras associadas ao CLAI (Conselho latino-americano de igrejas) se deslocaram de posicionamentos tradicionais dentro do meio missionário protestante, passando a assumir perspectiva ecumênica, apoiando o movimento indígena.

Além do papel da Teologia da Libertação e do crescimento interno da força dos movimentos étnicos a partir da década de 1970, o próprio cenário internacional contribuiu para o fortalecimento de reivindicações de respeito às autonomias étnicas na Bolívia. Isso porque, mesmo antes do final da Segunda Guerra Mundial, as potências envolvidas no conflito começaram a elaborar um sistema internacional que, por meio da cooperação entre sujeitos internacionais, pudesse trabalhar para impedir o surgimento de novas experiências totalitárias, como a ensejada pelo nazismo alemão, quando o slogan da necessidade de 
homogeneidade e da igualdade baseada na supressão das diferenças, levou ao extermínio de milhares de pessoas em campos de concentração. Assim, antes da Segunda Guerra Mundial, a ideia de Direitos Humanos se encontrava adstrita aos Estados, encontrando limites na soberania estatal. Somente no século XX, após o fim da Segunda Guerra, surgiu o movimento de internacionalização dos direitos humanos, quando a proteção da pessoa humana passou a ser objeto de atenção da comunidade internacional (GUERRA, 2012, p. 263).

\section{O DIREITO INTERNACIONAL E OS TRATADOS SOBRE DIREITOS INDÍGENAS NA BOLÍVIA}

Após a Segunda Guerra Mundial, o Direito Internacional, até então fundamentado na coexistência independente entre os Estados, passou a um Direito baseado na necessidade de cooperação para o alcance de objetivos comuns, ensejando a criação de organismos internacionais que fossem capazes de atuar por meio de governança e especialização em determinadas áreas, agindo dentro dos limites de seus estatutos, com o poder de impor sanções aos Estados-membros da sociedade internacional (GUERRA, 2012, p. 264).

Como decorrência deste processo, a Criação da ONU (Organização das Nações Unidas) em 1945 e a elaboração da Declaração Universal dos Direitos Humanos (1948) foram o início de um sistema internacional de proteção aos Direitos Humanos ${ }^{* *}$. Isso porque, a Declaração dos Direitos Humanos (1948), em seu Art. 1 afirma "o princípio de igualdade de direitos e de autodeterminação dos povos" o que suscitou inúmeros debates, ensejando o questionamento quanto ao conceito de "povo" e "autodeterminação", uma vez que as correntes majoritárias compreendiam a necessidade dos elementos estabelecidos pela Convenção de Montevidéu sobre Direito dos Estados de 1933, com elementos tradicionais

\footnotetext{
** Ao tratarmos da temática dos direitos humanos e dos direitos indígenas no cenário internacional e boliviano, devemos observar que os estudos que envolvem o tema se inserem entre as categorias "Direitos Humanos" e "Direitos Fundamentais", cabendo, acima das distinções teóricas entre os dois conceitos, considerar a afirmação de Ingo Wolfgang Sarlet de que "não há dúvidas de que os direitos fundamentais, de certa forma, são também sempre direitos humanos, no sentido de que seu titular sempre será o ser humano, ainda que representado por entes coletivos". Em sua obra, Sarlet realiza distinção entre os termos Direitos Humanos e Direitos Fundamentais, em que se aplica para estes, os direitos dos seres humanos, reconhecidos e positivados na esfera do Direito Constitucional de determinado Estado. Por sua vez, Direitos Humanos seriam aqueles que historicamente teriam relação com os documentos de Direito Internacional, com posições jurídicas que se reconhecem ao ser humano como tal, independentemente de sua vinculação com determinada ordem constitucional, tendo como característica sua aspiração à validade universal (SARLET, 2004).
} 
como população, território e governo para o estabelecimento da autodeterminação, enquanto as correntes menos tradicionais defendiam o direito à autodeterminação sem a necessidade de sua vinculação com uma formação estatal.

Um dos primeiros tratados internacionais voltados à questão étnica foi a Convenção n 107 da OIT, de 05 de junho de 1957, que objetivou a proteção e integração das populações indígenas à sociedade nacional, estabelecendo em seu Art. $1^{\circ}$ um conceito de integração que expressa claramente a necessidade de que os grupos "tribais" e "semitribais" perdessem tais características. Como a própria designação da convenção indica, seu caráter foi de integração dos povos indígenas aos aspectos dominantes nas sociedades nacionais em que estavam inseridos, considerando a cultura indígena como um elemento que leva seus participantes a estar "à margem do progresso". O mesmo documento, em seu Art. $4^{\circ}$ estabelece a necessidade de "empenhar-se em aplainar as dificuldades experimentadas por essas populações na adaptação a novas condições de vida e trabalho" e ainda "tomar consciência do perigo que pode advir da subversão dos valores e das instituições das referidas populações, a menos que os mesmos possam ser substituídos de maneira adequada e com o consentimento dos grupos interessados". Desta maneira, a Convenção 107 da OIT, embora tenha o mérito de estabelecer parâmetros para a saúde e educação indígena, se fundamentou na integração das populações indígenas aos valores ocidentais capitalistas como forma de alcance do progresso "desejável" a esses povos (GENEBRA, 1957).

Em 1971, foi realizado o Simpósio sobre Fricção Interétnica na América do Sul, do qual resultou a Declaração de Barbados DE 1971, documento em que antropólogos reunidos declararam o fracasso das políticas indigenistas dos Estados tanto por suas ações, quanto por suas omissões, a realidade de perpetuação do colonialismo em relação ao indígena, a denúncia de atos genocidas, o direito anterior das populações indígenas em relação à toda a sociedade nacional, o direito ao registro comunal de suas terras, o direito ao autogoverno. Além disso, denunciou o conteúdo etnocêntrico das atividades evangelizadoras e convocou as missões religiosas à libertação do indígena, por meio do respeito cultural. Não obstante a importância das denúncias efetivadas na Declaração de Barbados, servindo como norte para a ação de pesquisadores e demais envolvidos nas questões indígenas, além de exercer pressão sobre os Estados, sabemos que tal declaração não teve o poder de vinculação ou sanção das políticas estatais de assimilação e discriminação dos grupos étnicos. 
O tratado conhecido como Convenção 169 sobre Povos Indígenas e Tribais, elaborado durante a Conferência Geral da Organização Internacional do Trabalho, realizada em 1989, na cidade de Genebra, parece ser um divisor de águas em relação aos documentos internacionais sobre o direito indígena, visto que rechaçou as políticas de assimilação forçada, reconhecendo a existência de vários povos no interior de um mesmo Estado, estabelecendo novas formas de relação entre os Estados e os povos indígenas, possibilitando a construção de Estados pluralistas, estabelecendo o fim do modelo de tutela indígena, reconhecendo aos povos indígenas o direito de controlar suas próprias instituições políticas, culturais e sociais, determinando ainda a necessidade de consulta prévia, livre e informada, e a participação indígena em todas as políticas e programas que lhe digam respeito (VERDUM, 2010, p. 38).

Neste documento, a utilização do termo "povos indígenas" foi aprovada ressalvando a sua utilização para fins de Direito Internacional, ou seja, impossibilitando a compreensão do termo "povo" para a declaração de novos Estados, pois que o termo "povo" ligado às diferentes etnias ensejava conflito entre os juristas internacionalistas, visto que durante muito tempo o mesmo termo figurou como um dos pressupostos para a configuração de novos estados soberanos. Este aspecto é severamente criticado por pensadores como Díaz-Polanco, que vislumbra tal limitação como a confirmação de uma visão de "segunda classe" para os povos indígenas diante dos Estados Nacionais. Não obstante esta polêmica, o documento estabeleceu um rol de direitos humanos, enfatizando a necessidade de respeito à integridade dos valores, práticas e instituições dos povos indígenas (DÍAZ-POLANCO, 1998, p. 7).

O surgimento de tratados internacionais sobre direitos indígenas levou ao fortalecimento jurídico das demandas dos indígenas bolivianos, ao passo que e a redemocratização do país em 1982 possibilitou a ampliação dos espaços de debate e de expressão dos movimentos, além do fortalecimento de organizações indígenas já existentes e o surgimento de outras, acirrando e intensificando as lutas pelo reconhecimento de direitos e Princípios dos povos indígenas pelo Estado.

\section{AS ORGANIZAÇÕES INDÍGENAS BOLIVIANAS E O NOVO ÉTNICO}

Como já apontamos, o "massacre do vale" em 1974 se destaca como ponto de ruptura entre camponeses indígenas e a estrutura sindical criada pelo MNR em 1952, por meio do Pacto Militar-Camponês, dando espaço ao crescimento do movimento katarista de 
retomada da consciência étnica indígena na Bolívia. Esse processo de ruptura teve seu auge no VI Congresso da CNTCB (Confederación Nacional de los Trabajadores Campesinos de Bolivia) em 1977, quando Jenaro Flores, assumiu a posição de secretário executivo da organização, em aberta afronta às lideranças aliadas ao governo de Banzer, modificando o nome da organização para Confederação Nacional de Trabalhadores Camponeses Tupak Katari.

Mais tarde, em 1979 a CNTCB - Tupak katari, juntamente com a COB (Central Obreira Boliviana) realizaram um congresso em que foi aprovada a criação da CSUTCB (Confederação Sindical Única de Trabalhadores Camponeses da Bolívia), sob a direção de Jenaro Flores, demonstrando a disposição de seus participantes em atuar de maneira independente, aglutinando trabalhadores, camponeses e povos originários (CSUTCB, 2019). Segundo García Linera, a formação da CSUTCB propiciou a ampliação da autonomia das estruturas organizativas comunais dispostas em sindicatos desde a Revolução de 1952, dando maior visibilidade a estas estruturas que em alguns momentos ganham força nacional, reforçando e unindo demandas e propostas comunitárias agrárias da maioria dos departamentos (GARCÍA LINERA, 2010, 131).

Já no primeiro ano de sua formação, em primeiro de novembro de 1979, tanques tomaram o palácio do governo sob a liderança do coronel Alberto Natusch Busch (com o apoio de alguns membros do MNR), derrubando o governo constitucional de Walter Guevara, que vinha realizando ações de abertura política. Neste momento, a CSUTCB demonstrou sua força de mobilização, atuando juntamente com a COB (Central Obreira Boliviana), à frente da greve geral, convocando o bloqueio de estradas e demais manifestações que impediram o sucesso do golpe de Estado e levaram à renúncia de Natusch Busch, depois de duas semanas de detenções e mortes de vários membros da organização (GARCÍA LINERA, 2010, 61).

A CSUTCB teve papel preponderante na luta pela democratização do país, , com vários enfrentamentos entre os membros da organização e o exército, principalmente durante o golpe militar de García Meza em 1980, permanecendo em luta durante todo o processo até a reabertura política em 1982 (RIVERA CUSICANQUI, 2010, 209).

Em 1982 nasceu a Central de Povos e Comunidades Índígenas do Oriente Boliviano (Chiquitanos, Ayoreos, Guaranis, Guarayos), com a perspectiva de fortalecimento da unidade 
e estrutura organizativa de comunidades indígenas por meio das formas ancestrais e tradicionais de organização. Mais tarde adotou o nome de Confederação de Povos Indígenas da Bolívia, representando 34 povos indígenas das terras baixas, aglutinando povos indígenas do Oriente, Chaco e Amazônia boliviana (CIDOB, 2019).

A CIDOB (Confederação Indígena do Oriente, Chaco e Amazônia Boliviana) teve como base organizativa as comunidades, entendidas como agrupamento de várias famílias que compartilham um território comum para a produção familiar e de autoridades que regulam a convivência coletiva, por vezes com um ancestral comum e um conjunto de práticas compartilhadas. As comunidades elegem suas lideranças por meio de seus processos e tradições locais, sendo reunidas em um complexo de instâncias maiores até chegar em encontros de segundo nível, conhecidos como Assembleias do Povo Guarani (APG) ou Central de Povos (CPIB), caracterizadas pelo caráter multiétnico, com vários povos, várias identidades culturais, idiomas diferenciados (GARCÍA LINERA, 2010, P. 211).

Anos mais tarde, surgiu a ideia de criação de uma organização para representação das populações guaranis, utilizando o nome tradicional de suas assembleias gerais, as “Assembleias do Povo Guarani”. Esse processo de pensar e formar uma nova organização contou com o apoio da Igreja Católica, por meio de organizações como a Caritas e das paróquias de população guarani, além de organizações que já atuavam junto aos indígenas da região, como o Centro de Investigação e Promoção do Campesinato (CIPCA), Arakuarenda ${ }^{\dagger \dagger}$ e a própria CIDOB (CAUREY, 2015, p. 14) .

Em fevereiro de 1987, no centro Arakuarenda, com a participação de representantes de diferentes zonas de população guarani e representantes de organizações como CIPCA, CIDOB e da paróquia de Charagua, nasceu a APG (Assembleia do Povo Guarani da Bolívia), motivados pelo objetivo de reivindicar direitos sobre territórios e desenvolver as comunidades. A organização passou a ser feita por meio de assembleias comunais, zonais, e pela grande Assembleia, que se reune a cada dois anos, quando são eleitos os executivos da APG, realizando o planejamento da nova gestão, com a participação de mais de 24 zonas. As

\footnotetext{
${ }^{\dagger}$ Arakuarenda quer dizer lugar onde se educa e se forma. É um importante centro de formação localizado em Charagua (CAUREY, 2015. p. 14). Disponível em: <https://arakuaarenda.org/panel/wpcontent/uploads/2018/02/Asamblea-del-Pueblo-Guarani.-Elias-Caurey.pdf>. Acesso em: 22 jul. 2019.
} 
reuniões zonais se realizam a cada dois meses, convocada pelo capitão da zona ou “Mburivicha zona" (Procesos de Organización, 2019).

Já o CONAMAQ (Conselho Nacional de Ayllus e Markas do Qullasuyu) surgiu em março de 1997, depois de várias reuniões de autoridades originárias de ayllus das terras altas. Se identifica como máxima instância de representação das nacionalidades e povos indígenas das terras altas da Bolívia, tendo como característica um apelo maior à forma histórica de organização andina, rechaçando a participação por meio de sindicatos camponeses/indígenas. Segundo a visão de Albó, o CONAMAQ nasceu “de cima” contando com o apoio de vários intelectuais e profissionais aimarás urbanos, com um discurso étnico mais elaborado (ALBÓ, 2002, p. 185).

O CONAMAQ apresenta um esforço em manter as instituições e nomes tradicionais dos ayllus de cada região. Assim, apresenta uma posição crítica que se inicia com a maneira de nomear as regiões, petições, instrumentos de luta e até a forma de atuar dos sindicatos camponeses, proclamando o desenvolvimento de formas autodeterminadas de ação e a reconstituição de suas próprias autoridades. Um princípio muito forte nesta organização é a luta pelo meio ambiente e para que os povos originários tenham um rol histórico próprio, visto que os ayllus se mantiveram ao longo do tempo, devendo fundamentar-se em suas próprias instituições sociais, econômicas e culturais, sublinhando seu caráter multiétnico e pluricultural. A partir da presença de ayllus das zonas do altiplano sul, que resistiram à adesão ao sistema sindical iniciado com a Revolução de 1952, o CONAMAQ é em grande parte fruto do esforço dos próprios ayllus, juntamente com instituições não governamentais como o THOA $^{\text {\# }}$ (Taller de Historia Oral Andina) para manter vivos os modos de nomear e exercer a autoridade tradicional das comunidades. O CONAMAQ apresenta como principal tática a negociação, por meio da elaboração de documentos e propostas junto aos órgãos governamentais, e a sua atuação será importante durante a assembleia constituinte boliviana (GARCÍA LINERA, 2010, p. 324).

\footnotetext{
\# O Taller de Historia Oral Andina (THOA) foi fundado em 13 de novembro de 1983, dentro do Curso de Sociologia. Um grupo de estudantes em sua maioria aimarás que passaram pelo curso da Superestrutura Ideológica com Silvia Rivera Cusicanqui, a proponente da THOA, foi recrutado para estudar e investigar a participação indígena em revoltas, resgatando a consciencia e a história indígena baseadas na tradição oral. (THOA, 2019).
} 
Outro movimento com grande poder de mobilização na Bolívia a partir da década de 1980 foi o movimento liderado por cocaleiros da região do Chapare, cuja existência está intrinsecamente relacionada à colonização e à Reforma Agrária implementada pelo MNR em 1953. A região de Cochabamba que abarca as províncias de Chapare, Carrasco e Tiraque era pouco povoada até o início do século XX. Até o final do séc. XIX o governo boliviano pagava 10 centavos para aqueles que fossem capazes de colocar um habitante por milha. A partir de 1953, quando famílias de colonizadores começaram a chegar ao Chapare em maior quantidade, uniam-se a outras famílias próximas formando sindicatos (com aproximadamente 200 pessoas) para cuidar da distribuição das terras, abrir caminhos, realizar mutirões de trabalho (GARCÍA LINERA, 2010, p. 93).

A partir de 1965 apareceram mais sindicatos. Estes sindicatos, devido à grande quantidade de participantes, se dividiram em outros e formavam centrais. Estas centrais, que costumam ter entre 10 até 60 sindicatos, formaram a Federação Especial do Trópico em 1968 (província Chapare) afiliada à Confederação Sindical de Colonizadores de Bolívia (CSCB) e à COB (GARCÍA LINERA, 2010, p. 390).

Quanto ao plantio da folha de coca entre os colonizadores da região, este foi incentivado pelo programa de colonização iniciado pelo MNR em 1953, mas foi na década de 1970 que a expansão do cultivo para comercialização aconteceu. Não obstante o contínuo crescimento da cultura da folha de coca no país, a partir da década de 1960 é possível identificar ações governamentais em relação ao combate às plantações. A partir de 1986 teve início o Plano Trienal de Luta contra o Narcotráfico, que estabelecia que o combate ao narcotráfico se daria por meio da erradicação das plantações de coca. O plano previa a erradicação das plantações e também a militarização da área do Chapare com o envio de efetivos norteamericanos, equipamentos de logística, iniciando enfrentamentos entre cocaleiros e polícia, com várias mortes, detenções e outros desrespeitos de direitos da população local (GARCÍA LINERA, 2010, p. 386 - 387).

Este contexto fez com que os sindicatos, que tinham uma existência dedicada a assuntos domésticos de cada localidade, se organizassem frente ao Estado, defendendo a liberdade do cultivo da folha de coca. Os enfrentamentos entre cocaleiros e polícia continuou durante o final da década de 1980 e toda a década de 1990. Durante a década de 1990 e os 
primeiros anos do presente século, as federações do trópico cochabambino se converteram no epicentro das mobilizações sociais e dos enfrentamentos com o exército, assumindo um discurso de sacralidade da folha de coca e de seu uso ancestral indígena, unindo-se a outros organizações indígenas para a busca de direitos e a defesa da necessidade de uma nova constituição para a Bolívia (GARCÍA LINERA, 2010, p. 400).

Para Camille Goirand, tais movimentos étnicos, logo nomeados como "novos movimentos sociais", apresentam realmente traços de inovação desde suas características, definição de seus anseios até a formação, configuração, estrutura e área de atuação que assumiram, com o declínio dos aspectos e características que estiveram ligados aos movimentos operários, afastando-se dos discursos fundamentados apenas nas relações de trabalho e de classe, demandando mudanças sociais mais profundas, afirmando-se na cultura e em princípios identitários para refletir sobre a necessidade de reestruturação dos valores da sociedade como um todo (GOIRAND, 2009, 332).

Segundo Maria da Glória Gohn, a teoria dos novos movimentos sociais surgiu por meio das reflexões de autores como Touraine, Offe, Melucci, Laclau e Mouffe, entre outros, que percebendo a inadequação dos conceitos do marxismo tradicional para análise dos movimentos sociais que passaram a ocorrer a partir da década de 1960 na Europa e na década de 1980 na América latina, buscaram compreender a influência da cultura, das lutas sociais cotidianas e as identidades criadas em meio aos movimentos sociais. Tais autores identificaram a cultura como elemento capaz de ir além do papel de conjunto fixo e predeterminado de valores herdados do passado, além de redimensionar a relação entre cultura e ideologia, deixando de conceituar a ideologia como falsa representação do real para identificá-la como conjunto de representações que configuraram uma visão de mundo (GOHN, 1997, p. 122).

O sujeito histórico que emerge nestes movimentos não é predeterminado pelas contradições do capitalismo ou direcionado por uma vanguarda partidária, ao contrário, formam-se sujeitos coletivos, em luta contra a discriminação de acesso aos bens da modernidade, mas, ao mesmo tempo, críticos de seus efeitos nocivos, numa ação baseada em valores comunitários, indo além da busca por direitos imediatos, ressaltando a necessidade de transformação da própria sociedade (GOHN, 1997, p. 124). 
Também segundo Laclau (1986), nestes movimentos o político deixou de ser um nível do social, tornando-se uma dimensão presente ao longo da cadeia de práticas que se estabelecem em sociedade, com uma forte politização da vida, deixando de ser um espaço fechado e homogêneo.

Camille Goirand também destaca a utilização de novos canais de participação, como redes sociais e mídias na internet, além de mobilidade heterogênea, com a participação dos movimentos étnicos em ambientes diversificados, operando na contestação da política estatal, ao mesmo tempo em que luta por espaços de maior atuação e transformação desta política, com algumas organizações que passaram por um processo de institucionalização, com seus dirigentes em funções governamentais ou transformando-se em partidos (GOIRAND, 2009, 239). Se por um lado, Gohn ressalta a recusa desses movimentos em repetir a tradicional política de cooperação entre as agências estatais e os sindicatos (aspecto presente em países como a Bolívia até a década de 1960), por outro, Goirand reafirma a "novidade" desses movimentos étnicos, se apropriando da política eleitoral.

\section{CONSIDERAÇÕES FINAIS:}

Diante do exposto até aqui, fica demonstrado que o processo histórico de reivindicação de direitos pelos povos indígenas na Bolívia passou por diferentes contextos históricos e políticos, assim como as políticas promovidas pelo Estado em suas várias tentativas de assimilação e integração dos indígenas. O modelo integracionista promovido pelo MRN a partir da década de 1950 foi a alavanca para a formação de grupos de indígenas que por meio do acesso à educação formal, passaram a utilizar as ferramentas do "homem branco" para recusar as promessas de prosperidade e o modelo de vida das cidades, reivindicando um retorno às origens étnicas indígenas e o distanciamento entre indígenas e os programas clientelistas promovidos pelo Estado. A busca pelo reconhecimento de direitos indígenas, após a redemocratização do país na década de 1980, levou à criação ou reorganização de diversas organizações indígenas, que passaram a atuar sob novas bases, em grandes marchas que cruzaram o país, bloqueios e participação na política eleitoral, utilizando-se das políticas eleitorais, ao mesmo tempo que reivindicavam um Estado baseado em princípios indígenas e no pluralismo jurídico, se apropriando do Direito como elemento 


\section{REFERÊNCIAS:}

ALBÓ, Xavier. Pueblos indios en la política. La Paz: Centro de Investigación y Promoción del Campesinado (CIPCA). 2002. p. 32. Disponível em: <http://www.bivica.org/upload/cultura-andina.pdf\#page=1>. Acesso em: 30 jun. 2018.

BARBADOS. Declaração de Barbados pela libertação do indígena de 1971. Disponível em: <https://docplayer.com.br/10849238-Declaracao-de-barbados-i-pela-libertacao-doindigena.html >. Acesso em: 23 jun. 2018.

BARRAGÁN, Rossana. La dinámica de las comunidades y la transmisión de la tierra. In:

BELLO, Alvaro. Etnicidad y ciudadanía en América Latina. La acción colectiva de los pueblos indígenas. Santiago de Chile: CEPAL, 2004.

CAUREY, Elias. Asamblea del Pueblo Guaraní: Un breve repaso a su história. Território Guarani. Bolívia. 2015. p. 14. Disponível em: <https://arakuaarenda.org/panel/wpcontent/uploads/2018/02/Asamblea-del-Pueblo-Guarani.-Elias-Caurey.pdf>. Acesso em: 22 jul. 2019.

CHOQUE, M. E.; MAMANI, C. R. Reconstitución del Ayllu y derechos de los pueblos indígenas: el Movimiento Indio en los Andes de Bolivia. In: TICONA ALEJO, E. (org.). Los Andes desde los Andes. La Paz: Ediciones Yachaywasi, 2003. p. 205.

CIDOB. História. Disponível em: <http://www.apcbolivia.org/org/cidob.aspx>. Acesso em: 15 jan. 2019.

CSUTCB. História. Disponível em: <http://csutcb.org/node/102>. Acesso em: 15 jan. 2019.

DÍAZ-POLANCO, Héctor. Autodeterminación, autonomía y liberalismo. In: Autonomías Indígenas - Diversidad de Culturas, Igualdad de Derechos. Serie Aportes para el Debate. n. 6, 1998. p. 07.

DO ALTO, Hervé. Cuando el nacionalismo se pone el poncho. In: Maristella Svampa; Pablo Stefanoni (org.). Bolivia: Memoria, Insurgencia y Movimientos Sociales. Buenos Aires:

Clacso, 2007. p. 31.

ESCARZÁGA, Fabiola. Comunidad indígena y revolución en Bolivia: el pensamiento indianista-katarista de Fausto Reinaga y Felipe Quispe. Política y Cultura. México, D. F., n. 37, p. 185-210, 2012. Disponível em: <http://www.redalyc.org/articulo.oa?id=26723182009>. Acesso em: 25 set. 2017.

GARCÍA LINERA, Álvaro. Sociología de los movimientos sociales en Bolivia. Estructuras de movilización, repertorios culturales y acción política. La Paz: Plural Editores, 2010. p. 51. 
Álvaro. La potencia plebeya: acción colectiva e identidades indígenas, obreras y populares en Bolivia. Bogotá: Siglo del Hombre Editores y Clacso, 2009. Disponível em: <http://bibliotecavirtual.clacso.org.ar/ar/libros/coedicion/linera/linera.pdf>. Acesso em: 25 set. 2016.

GENEBRA. Convenção 107 da OIT de 1957. Disponível em: < https://www.oas.org/dil/port/1957\%20Convenção\%20sobre\%20Povos\%20Indígenas\%20e\%2 0Tribais.\%20(Convenção\%20OIT\%20n\%20\%20107).pdf>. Acesso em: 18 jun. 2018.

GIANOTTEN, Vera. CIPCA y poder campesino indígena: 35 años de historia. La Paz: CIPCA, 2006. p.41.

GOHN, Maria da Glória. Teoria dos movimentos sociais: paradigmas clássicos e contemporâneos. São Paulo: Edições Loyola, 1997. p. 123.

GOIRAND, Camille. Movimentos sociais na América Latina: elementos para uma abordagem comparada. Estudos Históricos (Rio de Janeiro), v. 22, n. 44, p. 323-354, 2009.

GUERRA, Sidney. Curso de direito internacional público. 6. ed. Rio de Janeiro: Lumen Juris, 2012. p. 263.

LACLAU, Ernesto. Os Novos Movimentos Sociais e a Pluralidade do Social. Revista Brasileira de Ciências Sociais, vol. 01, nº 02. 1986.

LEMA, Ana María. De la buella al impacto: historia de la aplicación de la ley de participación popular em municipios con población indígena (Uribichá, Gutiérrez y Villa Montes). Santa Cruz: PIEB (mimeo). Apud INTURIAS CANEDO, Mirna Liz et al. Um espacio em construcción: Hacia la gestión territorial de la tierra comunitaria de origen Parapitiguasu. La Paz: FUNDACIÓN PIEB, Mayo 2003. p. 3. Disponível em: <http://www.pieb.com.bo/2016/BPIEB/BPIEB_18_64_Espacio.pdf>. Acesso em: 22 jul. 2019.

PANNAIN, Rafaela Nunes. A crise do Estado boliviano e a autonomia indígena. 2014. $299 \mathrm{f}$. Tese (Doutorado em Sociologia). Programa de Pós-graduação em sociologia, Faculdade de filosofia, Letras e Ciências Humanas da Universidade de São Paulo, São Paulo, 2014, p. 72. Disponível em: <http://www.teses.usp.br/teses/disponiveis/8/8132/tde-06042015-190057/ptbr.php>. Acesso em: 27 dez. 2018.

PROCESSOS DE ORGANIZACIÓN. ASAMBLEA DEL PUEBLO GUARANÍ. Disponível em:

<http://www.amazonia.bo/indigena_organizacion_completa.php?codigo_enviado=q84rvbgq Mqd+XiPpAOhtlGiYTd8TJoIwmEu95E+tYVQ=\&\&codigo_noticia=C2u9rFfuyZB8eMn9s0 K1AaayXL8Thszde5/XbbuadXY=>. Acesso em: 22 jul. 2019.

RIVERA CUSICANQUI, Silvia. Oprimidos pero no vencidos: luchas del campesinado aymara y qhechwa de Bolivia, 1900-1980. 4. ed. (versión actualizada) La Paz: La Mirada Salvage, 2010.p. 46. 
SARLET, Ingo Wolfgang. A eficácia dos direitos fundamentais. 4 ed. Porto Alegre: Livraria do Advogado Editora, 2004.

THOA. História. Disponível em: < https://thoabolivia.wordpress.com/about/>. Acesso em: 16 jan. 2019.

URIOSTE, Miguel et al. Los nietos de la reforma agraria. La Paz: Fundación Tierra, CIPCA, 2007, p. 27-28.

URUGUAI. Convenção sobre Direitos e Deveres dos Estados de 1933. Disponível em: $<$ http://honoriscausa.weebly.com/uploads/1/7/4/2/17427811/convencao_sobre_direitos_e_dev eres_dos_estados-12.pdf >. Acesso em: 25 jun. 2018.

VALLE. Aline de Souza Vasconcellos do. Descolonialidade do Poder: Pluralismo Jurídico e autonomia indígena no Estado Plurinacional da Bolívia. In: COSTA, Adriane Vidal; REIS, Mateus Fávaro. (Org.). Anais do XIII Encontro Internacional da Associação Nacional de Pesquisadores e Professores de História das Américas [E-book]. 2018.UFOP. Mariana.

VERDUM, Ricardo. Novo Constitucionalismo e direitos indígenas na América Latina. Revista da Faculdade de Direito da FMP. n. 05, 2010, p. 28. 